\title{
Parameter-Independent Control for Battery Chargers Based on Virtual Impedance Emulation
}

\author{
Andoni Urtasun, Member, IEEE, Alberto Berrueta, Student Member, IEEE, \\ Pablo Sanchis, Senior Member, IEEE and Luis Marroyo, Member, IEEE
}

\begin{abstract}
An effective battery voltage regulation is fundamental to extend battery lifetime and to avoid overvoltage. However, the design of this regulation is complicated due to the wide battery impedance range, which, when dealing with universal chargers, is dependent not only on the operating point but also on the battery type and size. This paper first shows how the voltage response becomes highly variable when designing the controller as described in the literature. Then, it proposes to emulate virtual impedance in parallel with the battery, making it possible to achieve a voltage control which is independent of battery characteristics. Experimental results are carried out for a new lithium-ion battery with $25 \mathrm{~m} \Omega$-impedance and an overused lead-acid battery with $400 \mathrm{~m} \Omega$-impedance. For this large impedance variation, the results evidence the problems of the conventional control and validate the superior performance of the proposed control.
\end{abstract}

Index Terms-Battery charger, battery management, robust control, virtual impedance emulation, voltage control.

\section{INTRODUCTION}

$\mathrm{D}$ UE to the ongoing expansion of e-mobility and renewable-based systems, electrical storage systems are currently in the spotlight, of which batteries are the most commonly used thanks to their relatively high power density, efficiency and low cost. Battery applications in power systems include electric vehicles [1], [2], power dispatch control in photovoltaic plants and wind farms [3], [4], [5], stand-alone systems [6], [7], and microgrids [8], [9].

In these applications, the main concerns are related to system cost, where battery lifetime plays a major role [10], [11]. Many factors affect battery degradation, the most important being depth of discharge, number of cycles, battery temperature, current magnitude (C-rate) and voltage regulation

This work was supported by the Spanish State Research Agency (AEI) and FEDER-UE under grant DPI2016-80641-R.

The authors are with the Institute of Smart Cities, Department of Electrical and Electronic Engineering, Public University of Navarra, 31006 Pamplona, Spain (e-mail: andoni.urtasun@unavarra.es; alberto.berrueta@unavarra.es, pablo.sanchis@unavarra.es; luisma@unavarra.es).
[12]. As a result, one approach to extending battery lifetime could be to increase the battery capacity or to modify the energy management strategy, in order to reduce the depth of discharge or the number of cycles. This solution leads to an increase in other systems costs, which is usually addressed through an economic optimization [13], [14].

Another means to extend battery lifetime is to correctly perform battery charging. In fact, it is reported that improper charging induces the rapid buildup of internal stress and resistance, crystallization, and other negative effects [15][17]. Among the various methods, the most widespread are Constant-Current (CC)-Constant-Voltage (CV) charging for lithium-ion batteries [18], the Three Stage Charging (TSC) for lead-acid [19], [20], and flow batteries [21], [22].

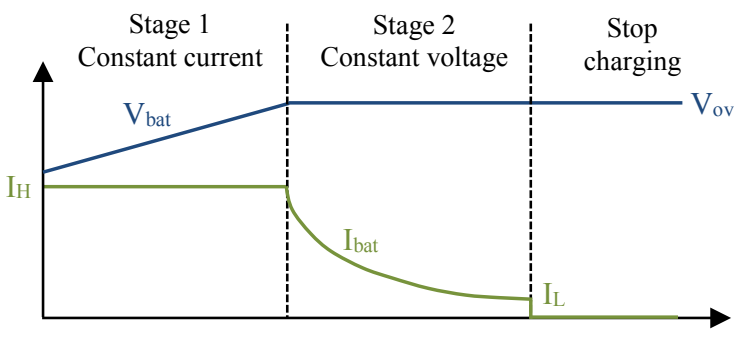

a) Lithium-ion battery

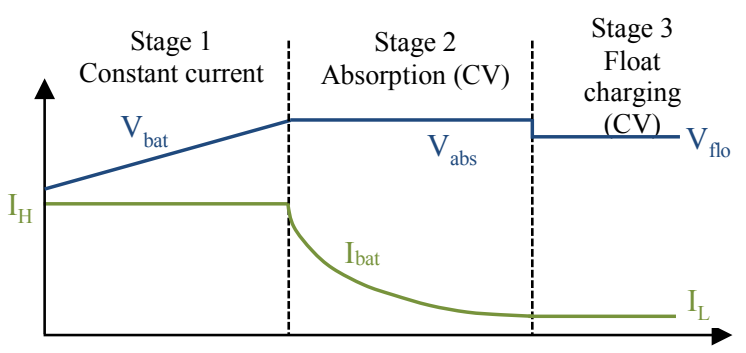

b) Lead-acid and flow batteries

Fig. 1. Battery charging methods: a) Constant-Current (CC)-Constant Voltage (CV) charging for lithium-ion batteries, b) Three Stage Charging (TSC) for lead-acid and flow batteries.

Although designed for different battery technologies, these two methods are essentially identical, as shown in Fig. 1. In both cases, the first stage is $\mathrm{CC}$ mode, where the battery current is either controlled to a certain value $I_{H}$ if power is available (for example in an electric vehicle charge) or to 
below this nominal value according to resource availability and energy management strategy (for example in a renewableenergy power plant or a microgrid). During this stage, both the battery voltage and the State-of-Charge $(\mathrm{SoC})$ increase. Then, when the voltage reaches a certain rated value, the charger control switches to CV mode, where the voltage is regulated. This rated voltage is provided by the battery manufacturer and, in the case of lithium-ion batteries, it is named overcharge voltage, while in the case of lead-acid and flow batteries, it is called absorption voltage. In this second stage, the battery current continuously decreases and the SoC continues to increase. For lithium-ion batteries, this is the last stage before stopping. However, for lead-acid and flow batteries, a third state, called float charging, is necessary. The charger control switches to this stage once the battery current becomes lower than a certain threshold $I_{L}$ and, from that moment onwards, the voltage is regulated to the float voltage [18]-[22].

As a result of the charging process, the converter interfacing the battery must be able to carry out both voltage and current regulations. For this purpose, two main control strategies are found in the literature, as shown in Fig. 2. In the first one, Fig. 2(a), the battery voltage and current are controlled by means of single feedback loops, where the controller output is in both cases the control voltage. Depending on the charging stage, the charge mode selector choses between $\mathrm{CC}$ or $\mathrm{CV}$ modes [23]-[25]. The second solution uses cascaded feedback loops, where the battery current is controlled in the inner loop, as represented in Fig. 2(b). The reference current is selected as the lowest between two values, namely $I_{b a t, C C}^{*}$, dedicated to control the current in CC mode, and $I_{b a t, C V}^{*}$, calculated by the outer loop, and dedicated to control the battery voltage in $\mathrm{CV}$ mode. During CC mode, $I^{*}$ bat,CC is selected and the outer loop is thus deactivated. Then, during CV mode, $I^{*}{ }_{b a t, C V}$ is selected and reduced below $I_{b a t, C C}^{*}$ in order to control the battery voltage [26]-[30].

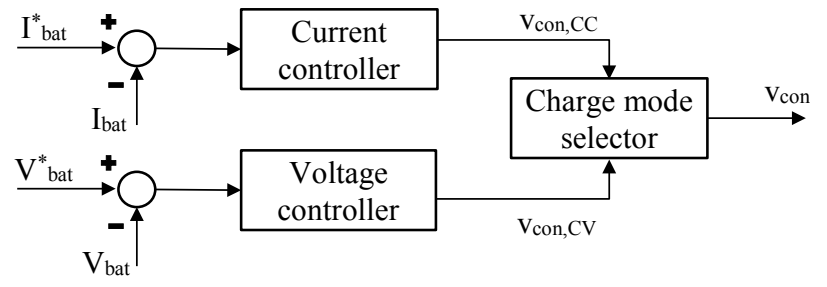

a) Two single feedback loops

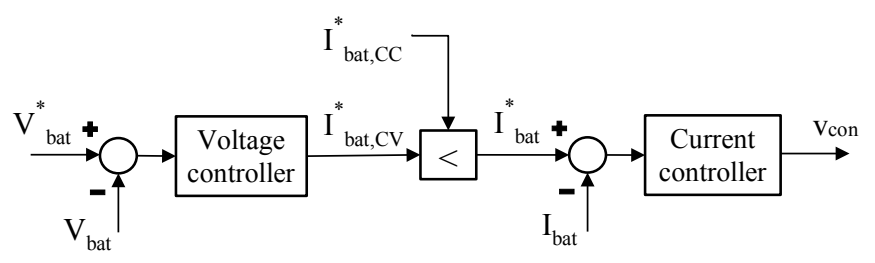

b) One cascaded feedback loop

Fig. 2. Battery voltage and current regulations: a) two single feedback loops, b) one cascaded feedback loop.

Excluding low power applications, the cascaded solution is preferred since the battery current is always controlled. This avoids current transients during voltage regulation and helps extend the battery and converter lifetimes. However, in this scheme, the design of the battery voltage regulation is complicated due to the wide battery impedance range which can be seen by the converter. Indeed, in a system with a predetermined battery, the impedance changes with the operating point, including $\mathrm{SoC}$, state-of-health and temperature. In addition, many battery manufacturers offer universal battery chargers, which are designed to be able to operate with different batteries. As a result, the impedance is also dependent on the battery technology and chemistry, as well as on the number of cells connected in series and parallel [31], [32].

Despite this fact, many authors design the voltage controller for a certain impedance value, without considering how impedance variation can affect the control [24], [26]-[28], [33], [34]. As will be shown in this paper, this leads to an extremely variable performance of the voltage control, which becomes either too slow or too fast at some operating points, and could even become unstable.

This variable dynamic performance is not critical when a dispatchable power source is available, such as in the case of an electric vehicle being charged from the grid. However, in renewable-energy-based stand-alone systems, the change from $\mathrm{CC}$ mode to $\mathrm{CV}$ mode can be abrupt as a result of an increase in the renewable resource or a load disconnection, causing an overvoltage in the battery [7], [35]. In order to relieve the damage on the battery, it is very important that the voltage regulation responds fast enough independently of the connected battery.

In order to achieve a robust control against parameter variations, non-linear control methods have been proposed in the literature. In [25], the battery voltage is regulated by using hysteresis control. Whereas the dynamic variability is reduced, this method presents low noise immunity and implies variable switching frequency. In [29] and [30], an adaptive control is proposed to be robust against battery resistance variation. The problem of this method is that a complex algorithm is required to estimate the resistance value. In [36], fuzzy logic is used in order to control the battery voltage. In this case, controller parameters must be experimentally tuned and control robustness is not assured [37].

This paper proposes a simple, linear and robust control for battery voltage regulation. A small virtual impedance in parallel with the battery is emulated in such a way that the control becomes almost independent of the battery impedance value. Given the present diverse range for battery types and sizes, this control is very useful since it makes it possible to use a universal charger. Compared to the other methods, the proposed control achieves constant switching frequency and the computational cost is very low since only a first-order filter and a subtraction needs to be added to the conventional PI controller.

The paper is organized as follows. Section II describes the problem of conventional chargers, showing how the battery impedance variation affects the voltage control performance. 
Section III presents the proposed control for different types of virtual impedances. Then, in section IV, experimental results are provided to verify the proposed regulation for the case of RL virtual impedance. Finally, the conclusions of this study are given in section $\mathrm{V}$.

\section{Description of the PROBlem}

The system analyzed is shown in Fig. 3 and consists of a battery connected to a boost converter. The output can vary depending on the application, which could be a voltage-fed inverter or an electric vehicle DC bus, for example. Although a capacitor is often included at the input to reduce the highfrequency current provided by the battery, as the capacitor is very small and does not affect the voltage regulation, it can be disregarded.

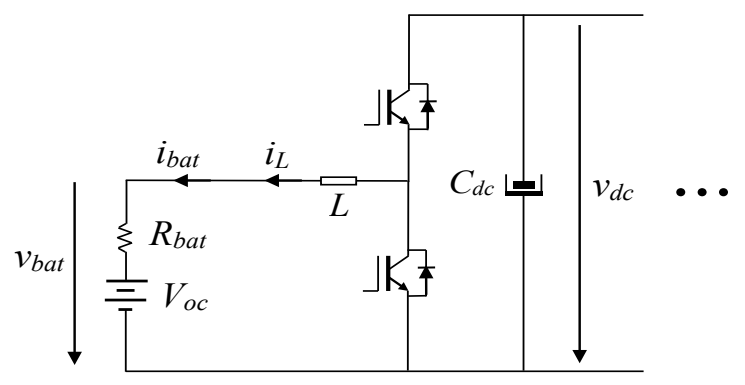

Fig. 3. Battery connected to a boost converter charger.

Thanks to its advantages for this application [29], the control scheme chosen for the battery charger is a cascaded feedback loop, as shown in Fig. 2(b). In this scheme, the inner inductor current loop can be easily made independent of the input impedance by using measured variables $v_{b a t}$ and $v_{d c}$ as feedforward compensations, as carried out in [38] and [39].

In contrast, it is obvious that the battery impedance does have an influence on the voltage regulation. The battery model usually considers an open-circuit voltage source, $V_{o c}$, in series with an internal resistance and one or more RC branches [28]. Since the variation of the open-circuit voltage is very slow, this source can be considered as a constant disturbance for the voltage regulation. Concerning the impedance, for low frequencies around the cutoff frequency of the voltage regulation, the model can be considered as pure resistance $R_{\text {bat }}$ [40], [41]. As a result, the small-signal plant to be controlled is

$$
Z_{\text {bat }}(s)=\frac{\hat{v}_{\text {bat }}}{\hat{i}_{\text {bat }}}=\frac{\hat{v}_{\text {bat }}}{\hat{i}_{L}} \approx R_{\text {bat }} .
$$

Since a universal battery charger is used, it is considered that the battery resistance is unknown for the control. The $R_{\text {bat }}$ value can be within a wide range and depends on the battery technology and chemistry, operating point, aging, and seriesparallel cells connection. In order to evaluate the performance of the battery voltage control, it is important to obtain the possible resistance range. For this purpose, the battery charger specifications, shown in Table I, must be taken into account.

From the various possibilities, the minimum battery resistance, $R_{b a t, m i n}$, occurs in a new lithium-ion battery, with low nominal voltage and high maximum current $(48 \mathrm{~V}, 50 \mathrm{~A})$, operating at high temperature $\left(50^{\circ} \mathrm{C}\right)[42]-[44]$. Taking into account commercial lithium-ion batteries, the mentioned conditions and the wire resistance, one obtains $R_{\text {bat, } \min }=10 \mathrm{~m} \Omega$.

TABLE I

SPECIFICATIONS OF THE BOOST CONVERTER CHARGER

\begin{tabular}{ll}
\hline Battery chemistry & Lithium-ion, lead-acid, flow \\
Nominal battery voltage & Between 48 and $240 \mathrm{~V}$ \\
Output voltage $V_{d c}$ & $350 \mathrm{~V}$ \\
Converter rated current & $50 \mathrm{~A}$ \\
Converter inductor $L$ & $750 \mu \mathrm{H}$ \\
Voltage controller sampling time $T_{s}$ & $4 \mathrm{~ms}$ \\
Time constant of the voltage sensing $\tau_{v}$ & $40 \mathrm{~ms}$ \\
Current controller sampling time & $125 \mu \mathrm{s}$ \\
Cutoff frequency of the current control & $450 \mathrm{~Hz}$ \\
Converter switching frequency & $16 \mathrm{kHz}$ \\
\hline \hline
\end{tabular}

On the other hand, the maximum battery resistance, $R_{\text {bat, } \max }$, can be found for an overused lead-acid battery, with high nominal voltage and low capacity $(240 \mathrm{~V}, 75 \mathrm{Ah})$, operating at low temperature $\left(-10^{\circ} \mathrm{C}\right)$ [45], [46]. In this situation, the maximum resistance for a commercial lead-acid battery becomes $R_{\text {bat, } \max }=1 \Omega$. As a result, it can be observed that the battery resistance value can be between $10 \mathrm{~m} \Omega$ and $1 \Omega$, i.e. within a rate of 100 , making it difficult to achieve a parameter-independent voltage regulation.

The most common method to control the battery voltage is by directly using an integral or PI controller [26]-[28], [33]. This method is very simple and its scheme is shown in Fig. 4, where $v^{*}$ bat is the reference battery voltage, $v_{b a t, m}$ the measured battery voltage, $i_{L}^{*}$ the reference inductor current, $C_{\mathrm{v}}$ represents the voltage controller, $S_{v}$ the voltage digital sampler, $\mathrm{G}_{\mathrm{icl}}$ the inductor current closed-loop and $\mathrm{H}_{\mathrm{v}}$ the voltage measurement.

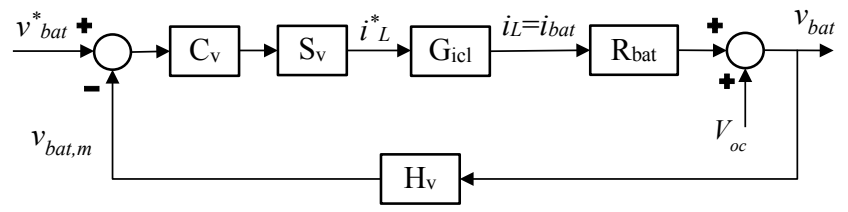

Fig. 4. Battery voltage control loop for the conventional control.

The digital sampler $\mathrm{S}_{\mathrm{v}}$ can be approximated as

$$
S_{v}(s)=\frac{1}{s / \omega_{s}+1}
$$

where $\omega_{\mathrm{s}}=1 /\left(1.5 \cdot T_{s}\right)$ and $T_{s}$ is the controller sampling time.

The voltage sensing transfer function $\mathrm{H}_{\mathrm{v}}$ can be expressed as

$$
H_{v}(s)=\frac{K_{v}}{s / \omega_{v}+1},
$$

where $\omega_{v}=1 / \tau_{v}, \tau_{v}$ is the time constant of the voltage sensing and $K_{v}$ is the scaling constant of the voltage sensing, which will be taken as 1 in order to simplify the analysis.

The inner inductor closed-loop can be approximated as a first order transfer function: 


$$
G_{i c l}(s)=\frac{1}{s / \omega_{c l}+1},
$$

where $\omega_{c l}$ is the angular cutoff frequency of the current control.

Concerning voltage regulator $\mathrm{C}_{\mathrm{v}}$, an integral controller is considered in this example, $\mathrm{C}_{\mathrm{v}}=K_{i} / \mathrm{s}$. Parameter $K_{i}$ is usually calculated by assuming that the system plant is (1) for a certain battery resistance value, without taking into account its variation range. In this case, the resistance is considered as the geometric mean between $R_{b a t, \min }=10 \mathrm{~m} \Omega$ and $R_{b a t, \max }=1 \Omega$, that is $R_{\text {bat,medium }}=100 \mathrm{~m} \Omega$. According to the battery features, a low cutoff frequency is required for the voltage regulation, and it is set to $f_{c}=0.5 \mathrm{~Hz}$.

The compensated open-loop for three different battery resistances with this integral controller is shown in Fig. 5. As can be observed, the voltage response is as designed, with $f_{c}=0.5 \mathrm{~Hz}$, only for $R_{\text {bat,medium }}=100 \mathrm{~m} \Omega$. However, it slows down to $f_{c}=0.05 \mathrm{~Hz}$ for $R_{b a t, \min }=10 \mathrm{~m} \Omega$, and speeds up to $f_{c}=3.7 \mathrm{~Hz}$ for $R_{b a t, \max }=1 \Omega$. With regard to stability, the Phase Margin (PM) decreases as the battery resistance increases, reaching a value of $\mathrm{PM}=39^{\circ}$ for $R_{b a t \text { max }}=1 \Omega$.

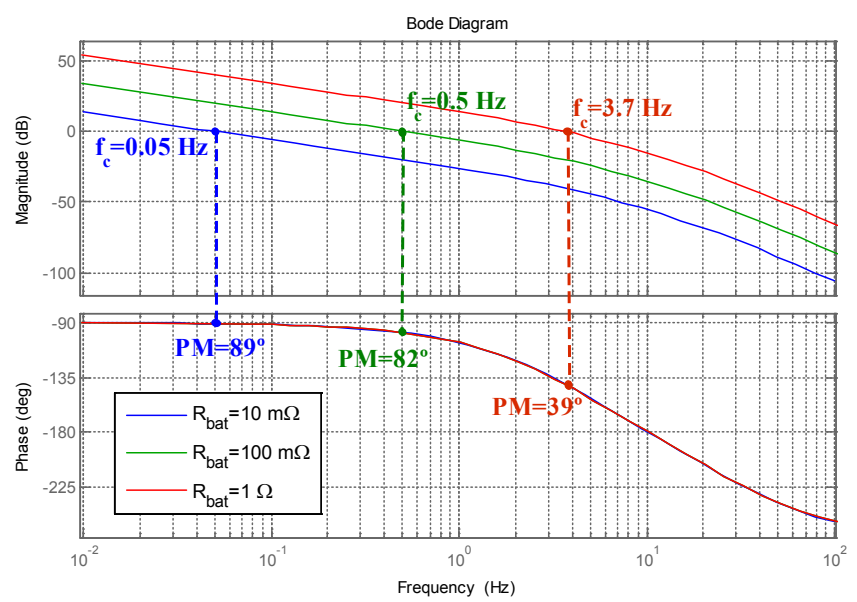

Fig. 5. Bode plot of the compensated open-loop for three different battery resistances, using the conventional control with an integral controller.

The conventional control is tested by using PSIM simulation software. The model includes the battery, a boost converter, and a single-phase inverter connected to the grid. The simulation results for three different battery resistances are shown in Fig. 6, where the reference voltage is modified so that the current increases from 0 to $20 \mathrm{~A}$ in the three cases. It can be observed that the response is very variable depending on $R_{b a t}$, specifically the rise time (from $10 \%$ to $90 \%$ for overdamped systems and from 0 to $100 \%$ for underdamped systems [47]) is $t_{r, 1 \Omega}=38 \mathrm{~ms}, t_{r, 100 \mathrm{~m} \Omega}=620 \mathrm{~ms}$, and $t_{r, 10 \mathrm{~m} \Omega}=6.8 \mathrm{~s}$. Indeed, the control is too far from the desired performance and is not suitable for some applications.

The fact that the control becomes very slow under certain conditions can cause a large and prolonged overvoltage in renewable-energy-based stand-alone systems. To show this problem, the conventional control is tested for a $25 \mathrm{~m} \Omega$ battery in a situation where the boost converter charger is connected to a photovoltaic-based stand-alone system, where the simulation results are shown in Fig. 7. At the beginning, the battery voltage is below the maximum value and, as a result, the reference current for $\mathrm{CV}$ mode, $I^{*}{ }_{b a t, C V}$, is saturated to the maximum value. Therefore, $\mathrm{CC}$ mode is selected and the outer voltage loop is deactivated. Then, at second 6, an irradiance rise occurs, causing the battery current and voltage to increase. It can be observed that the voltage control activation is belated and its response is very slow, provoking a large and prolonged overvoltage. As shown in the figure, the maximum battery voltage reaches $54.60 \mathrm{~V}$, well above the maximum voltage, and the duration of the overvoltage is very long (the voltage remains $3.1 \mathrm{~s}$ over $54.1 \mathrm{~V}$ ), which contributes to fast battery aging.
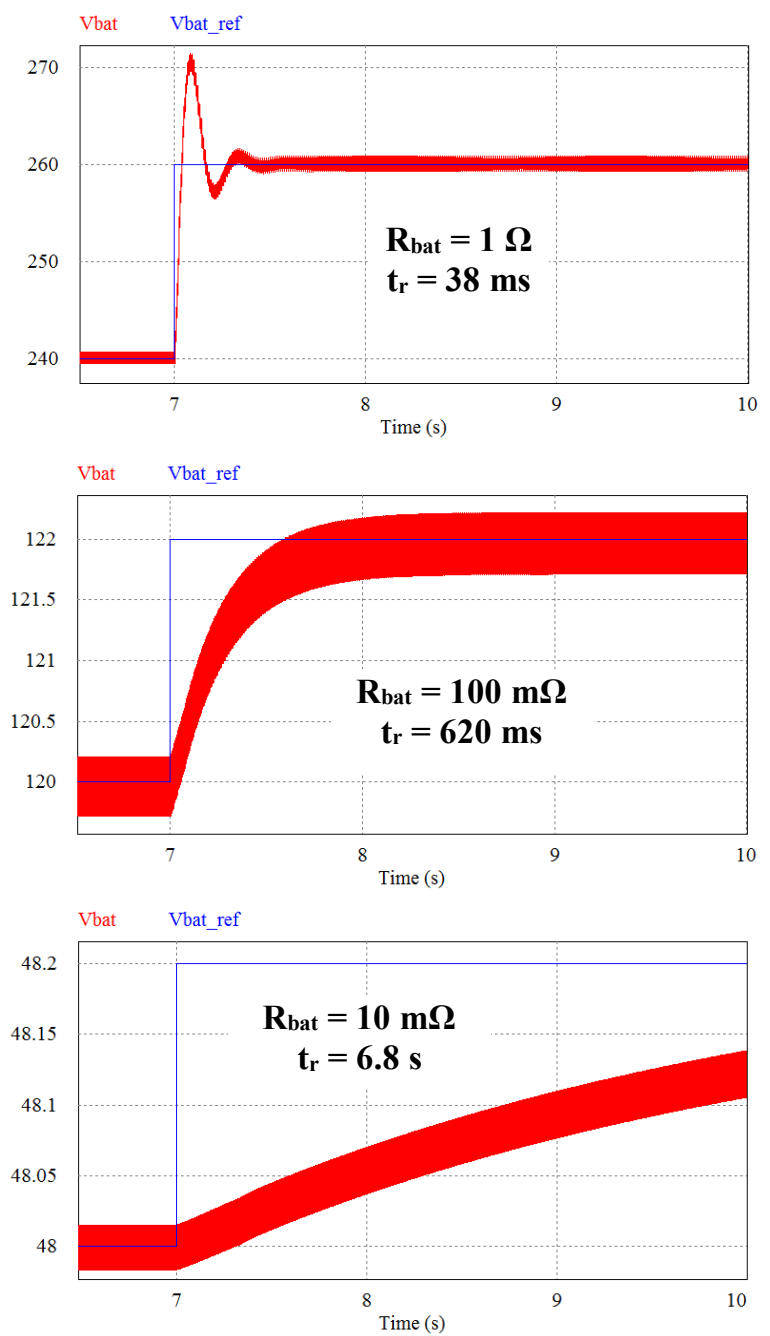

Fig. 6. Simulation results for the conventional battery voltage control for $R_{\text {bat, } \max }=1 \Omega, R_{\text {bat,medium }}=100 \mathrm{~m} \Omega$ and $R_{\text {bat, } \text { min }}=10 \mathrm{~m} \Omega$.

In order to compensate the wide resistance range, some authors have proposed non-linear control schemes [25], [29], [30], [36]. Although they do improve the robustness against parameter variations, these controls are either much more complex or are unable to maintain a constant switching frequency. 


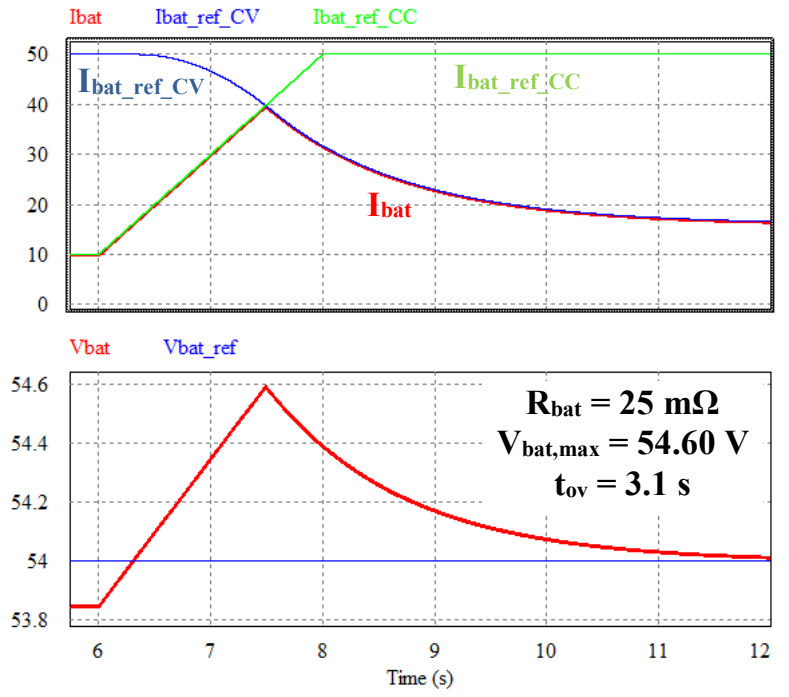

Fig. 7. Simulation results for the conventional battery voltage control after an irradiance rise, for $R_{b a t, \min }=25 \mathrm{~m} \Omega$.

\section{PRoposed METHOd}

\section{A. Description}

A straightforward strategy to reduce the influence of the battery resistance variation would be to add a small impedance, $Z_{\text {real }}$, in parallel with the battery. If this impedance is small enough around the frequencies of concern, then the system would behave as this known impedance, and thus the plant variability would be completely removed. In doing so, the plant becomes

$$
\begin{gathered}
Z_{\text {eq,real }}(s)=\frac{\hat{v}_{\text {bat }}}{\hat{i}_{L}}=R_{\text {bat }} / / Z_{\text {real }}(s) \\
Z_{\text {eq, real }}(s)=\frac{\hat{v}_{\text {bat }}}{\hat{i}_{L}} \approx Z_{\text {real }}(s), \text { if }\left|Z_{\text {real }}\left(j \cdot \omega_{c}\right)\right|<<R_{\text {bat }},
\end{gathered}
$$

where $\omega_{c}$ is the angular cutoff frequency of the battery voltage regulation.

By using this impedance, the battery voltage control loop is represented in Fig. 8(a), where $i_{\text {Zreal }}$ is the impedance current and $V_{o c}$ disturbance is omitted. Although this impedance is obviously too small for practical applications, it could be ideally emulated by calculating the impedance current as a function of the battery voltage. By means of this virtual impedance, $Z_{v}$, the voltage control is represented in Fig. 8(b), where $i_{Z v}$ is the virtual impedance current, and $i_{v}=i_{L}^{*}+i_{Z v}$ is the virtual current. By comparing the figures, it can be observed that, in reality, the impedance emulation is not exact because the measured voltage is used instead of the real voltage, and the reference current is modified instead of the real battery current. However, if it is assumed that the current closed-loop, the voltage sampling and the voltage measurement are fast enough, then both loops are equivalent. As a result, the battery resistance influence is also eliminated, with the advantage that real impedance is not required. In this case, the system plant is equivalent to (5) and (6), more specifically

$$
\begin{gathered}
Z_{\text {eq,approx }}(s)=\frac{\hat{v}_{\text {bat }}}{\hat{i}_{v}}=R_{b a t} / / Z_{v}(s) \\
Z_{\text {eq,approx }}(s)=\frac{\hat{v}_{b a t}}{\hat{i}_{v}} \approx Z_{v}(s), \text { if }\left|Z_{v}\left(j \cdot \omega_{c}\right)\right|<<R_{b a t} .
\end{gathered}
$$

With this approximation $\left(\mathrm{H}_{\mathrm{v}}=1, \mathrm{~S}_{\mathrm{v}}=1\right.$ and $\left.\mathrm{G}_{\mathrm{icl}}=1\right)$, the battery voltage control loop is represented in Fig. 8(c). This model describes the low-frequency behavior of the system and thus can be used to design the voltage controller. However, in order to model the high-frequency behavior, the current closed-loop, the sampling and the measurement transfer functions must be taken into account. In this way, the voltage control loop shown in Fig. 8(b) can be accurately modeled by considering the actual equivalent impedance, as shown in Fig. 8(d). From Fig. 8(b), this equivalent impedance can be obtained as

$$
Z_{e q}(s)=\frac{\hat{v}_{b a t}}{\hat{i}_{v}}=\frac{S_{v}(s) \cdot G_{i c l}(s) \cdot R_{b a t} \cdot Z_{v}(s)}{Z_{v}(s)+H_{v}(s) \cdot S_{v}(s) \cdot G_{i c l}(s) \cdot R_{b a t}} .
$$
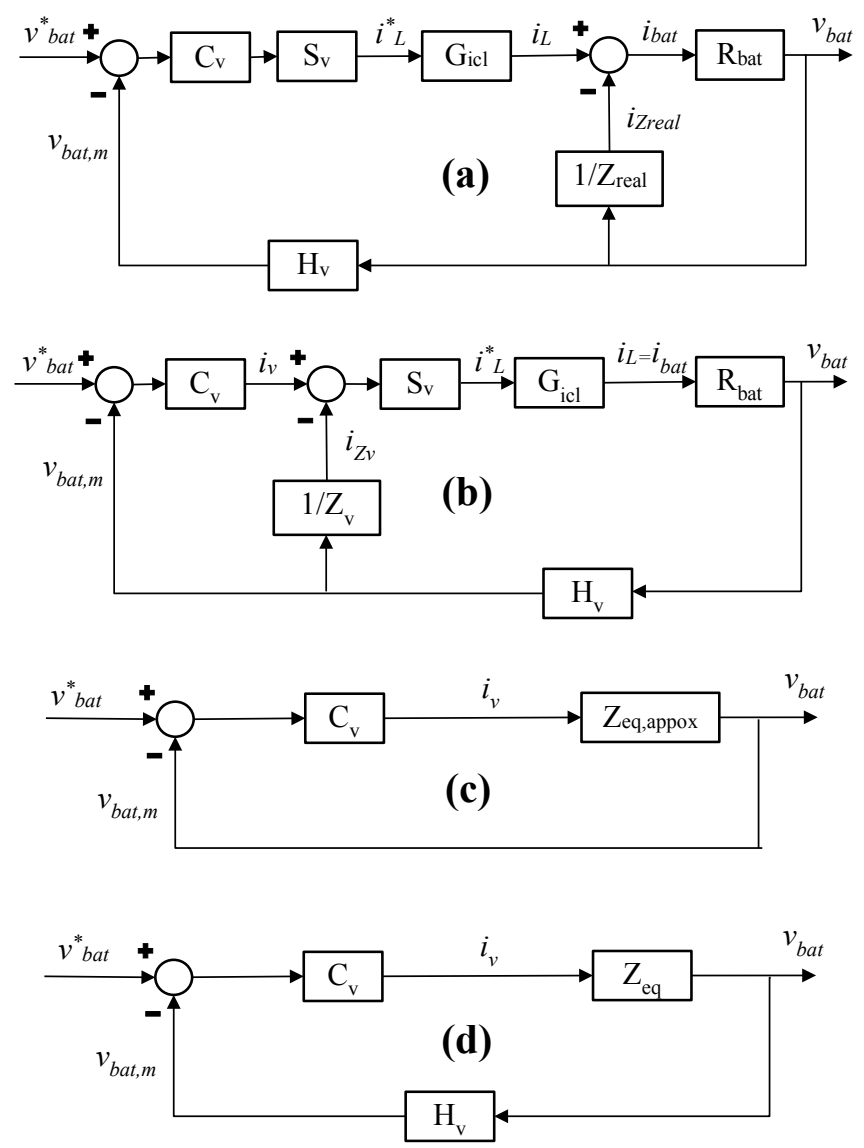

Fig. 8. Battery voltage control loops: (a) With a real impedance $Z_{\text {real }}$, (b) With a virtual impedance $Z_{v}$, (c) Approximate model with virtual impedance $Z_{v}$ and with $\mathrm{H}_{\mathrm{v}}=1, \mathrm{~S}_{\mathrm{v}}=1$ and $\mathrm{G}_{\mathrm{icl}}=1$, (d) Accurate model with virtual impedance $Z_{v}$.

Depending on the system parameters and virtual impedance $Z_{v}$, the equivalent impedance $Z_{e q}$ may include Right-HalfPlane (RHP) poles. Since the cutoff frequency is much lower, 
it would be impossible to stabilize the voltage regulation in such a situation. Therefore, when designing the virtual impedance, attention must be paid to avoiding RHP poles for the whole operating range of battery resistance $R_{\text {bat }}$. The Routh-Hurwitz stability criterion will be applied to the denominator of (9) in order to determine the presence of RHP poles.

\section{B. Choice of the Virtual Impedance}

The desired properties of the virtual impedance are:

- Low impedance around the cutoff frequency so that the battery resistance has no influence [see (8)].

- High impedance at high frequency in such a way that the voltage harmonics present in the battery voltage measurement are not amplified. This includes the measurement noise or the pulsation at twice the grid frequency present in single-phase systems.

- When using analog controllers, high impedance at DC in order to avoid a very high value of the DC virtual current. This condition is not important for digital implementations since a high virtual current is not physically present in any circuit and can be dealt with by the controller.

- Simple implementation.

- Interaction with the control loop so that the equivalent impedance $Z_{e q}$ has no RHP poles.

Among the various virtual impedances which can be envisaged for this application, Fig. 9 shows the most suitable ones, namely $R, R C, R L$ and $R L C$. In all cases, the impedances are designed to comply with the first property and thus have low values around $\omega_{c}$. The high-frequency impedance is high when an inductor is present ( $R L$ and $R L C$ ) but otherwise low due to the low $R$ value. The importance of this property in the real implementation makes it possible to disregard the $R$ and $R C$ impedances. The DC impedance is infinite when a capacitor is present and low in other cases, although this does not represent a problem in the case of a digital control. Digital implementation requires a constant gain for the $R$ impedance, a constant gain with a first-order high-pass filter for the $R C$ impedance, a constant gain with a first-order low-pass filter for the $R L$ impedance, and a second-order band-pass filter for the $R L C$ impedance. With regard to the appearance of RHP poles in the impedance $Z_{e q}$ [see (9)], the Routh-Hurwitz stability criterion has been applied, and the suitable range for the battery resistance is shown in Fig. 9, where two angular frequencies are defined as $\omega_{R C}=1 / R C$ and $\omega_{R L}=R / L$. Although the accuracy of the displayed conditions is sufficiently high for this application, it must be noted that they are not exact since they are obtained by alternately disregarding different dynamics.

Among the four possibilities, impedance $R L$ is chosen because of its adequate high-frequency behavior and its simple implementation. In order to design the $R$ and $L$ values, it should be considered that low values make it possible to obtain a low impedance around $\omega_{c}$ and thus reduce the battery resistance influence. On the other hand, high values are preferred in order to increase the high-frequency impedance and also to extend the allowable operating range by helping to prevent the appearance of RHP poles. Therefore, the values $R=35 \mathrm{~m} \Omega$ and $L=11.2 \mathrm{mH}$ are selected as a tradeoff. This leads to an allowable operating range for battery resistance $R_{b a t}<2.45 \Omega$, which falls within the actual operating range $\left(10 \mathrm{~m} \Omega<R_{\text {bat }}<1 \Omega\right)$.

\begin{tabular}{|c|c|c|c|c|c|}
\hline $\begin{array}{c}\text { Virtual } \\
\text { impedance } Z_{v}\end{array}$ & $Z_{v}$ around $\omega_{\mathrm{c}}$ & $\begin{array}{l}Z_{v} \text { at high } \\
\text { frequency }\end{array}$ & $Z_{v}$ at $\mathrm{DC}$ & $\begin{array}{c}\text { Digital } \\
\text { implementation }\end{array}$ & $\begin{array}{l}\text { Conditions to } \\
\text { avoid RHP poles }\end{array}$ \\
\hline $\begin{array}{l}\checkmark W \\
Z_{v}(s)=R\end{array}$ & $\begin{array}{l}\checkmark \text { W } \\
\checkmark \text { Low }\end{array}$ & $\begin{array}{l}\text { W } \\
\times \text { Low }\end{array}$ & $\begin{array}{l}\text { Wow } \\
\text { Low }\end{array}$ & $\checkmark$ Very simple & $R_{b a t}<R \cdot\left(\frac{\omega_{v}+\omega_{s}}{\omega_{c l}}+\frac{\omega_{v}+\omega_{c l}}{\omega_{s}}+\frac{\omega_{s}+\omega_{c l}}{\omega_{v}}+2\right)$ \\
\hline $\begin{array}{l}\neg W-\mid F \\
Z_{v}(s)=\frac{R \cdot C \cdot s+1}{C \cdot s}\end{array}$ & $\underset{\checkmark \text { Low }}{\longrightarrow \text { W }}$ & $\begin{array}{l}\text { Wh } \\
\times \text { Low }\end{array}$ & HF & $\checkmark$ Simple & $\begin{array}{l}R_{b a t}>\frac{1}{C} \cdot\left(\frac{1}{\omega_{v}+\omega_{s}+\omega_{R C}}-\frac{1}{\omega_{v}}-\frac{1}{\omega_{s}}-\frac{1}{\omega_{R C}}\right) \\
R_{b a t}<R \cdot\left(\frac{\omega_{v}+\omega_{s}}{\omega_{c l}}+\frac{\omega_{v}+\omega_{c l}}{\omega_{s}}+\frac{\omega_{s}+\omega_{c l}}{\omega_{v}}+2\right)\end{array}$ \\
\hline $\begin{array}{l}\longrightarrow W m \\
Z_{v}(s)=R \cdot(L / R \cdot s+1)\end{array}$ & $\begin{array}{c}\text { Whrm } \\
\checkmark \text { Low }\end{array}$ & $m$ & Low & $\checkmark$ Simple & $\begin{array}{l}R_{b a t}<R \cdot\left(\frac{\omega_{R L}+\omega_{v}}{\omega_{s}}+\frac{\omega_{R L}+\omega_{s}}{\omega_{v}}+\frac{\omega_{v}+\omega_{s}}{\omega_{R L}}+2\right) \\
R_{b a t}<L \cdot\left(\omega_{s}+\omega_{c l}\right)\end{array}$ \\
\hline $\begin{array}{l}\text { Whrt } \\
Z_{v}(s)=\frac{L \cdot C \cdot s^{2}+R \cdot C \cdot s+1}{C \cdot s}\end{array}$ & $\begin{array}{l}\checkmark \text { W } \\
\checkmark \text { Low }\end{array}$ & m & $\begin{array}{l}-1 F \\
\text { High }\end{array}$ & - Medium & $\begin{array}{l}R_{b a t}>\frac{1}{C} \cdot\left(\frac{1}{\omega_{v}+\omega_{R L}}-\frac{1}{\omega_{v}}-\frac{1}{\omega_{R C}}\right) \\
R_{b a t}<R \cdot\left(\frac{\omega_{R L}+\omega_{v}}{\omega_{s}}+\frac{\omega_{R L}+\omega_{s}}{\omega_{v}}+\frac{\omega_{v}+\omega_{s}}{\omega_{R L}}+2\right) \\
R_{b a t}<L \cdot\left(\omega_{s}+\omega_{c l}\right)\end{array}$ \\
\hline
\end{tabular}

Fig. 9. Comparison among R, RC, RL and RLC virtual impedances for digital controllers. 
By using this RL virtual impedance, the bode plot of equivalent impedance $Z_{e q}$ is shown in Fig. 10 for three different battery resistances $\left(R_{\text {bat }, \text { min }}=10 \mathrm{~m} \Omega\right.$, $R_{\text {bat, } \text { medium }}=100 \mathrm{~m} \Omega, R_{\text {bat, } \max }=1 \Omega$ ), and for the ideal case with $R_{\text {bat }} \rightarrow \infty, \mathrm{H}_{\mathrm{v}}=1, \mathrm{~S}_{\mathrm{v}}=1$ and $\mathrm{G}_{\mathrm{icl}}=1$, in which $Z_{e q}=Z_{v}$. As can be observed, around $0.5 \mathrm{~Hz}$, the plants for $R_{\text {bat,medium }}=100 \mathrm{~m} \Omega$ and $R_{b a t, \max }=1 \Omega$ behave as the virtual impedance while the plant for $R_{\text {bat,min }}=10 \mathrm{~m} \Omega$ behaves as the virtual impedance in parallel with the battery resistance. Thus, thanks to the proposed method, the impedance variation at the frequencies of concern has been greatly reduced, particularly form a ratio of 100 to 5.5 .

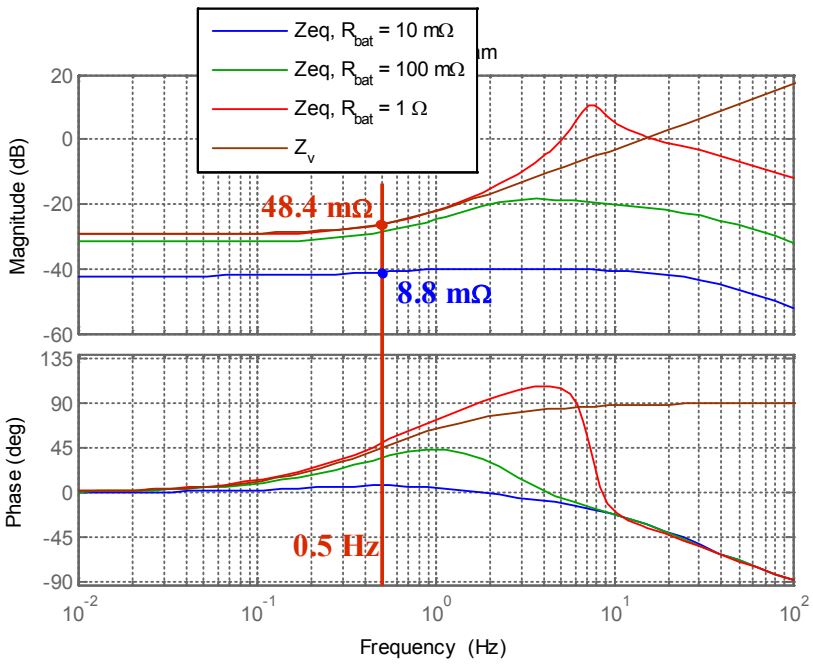

Fig. 10. Bode plot of the equivalent impedance $Z_{e q}$ for $R_{b a t, \min }=10 \mathrm{~m} \Omega$, $R_{\text {bat, } \text { medium }}=100 \mathrm{~m} \Omega, R_{\text {bat } \text { max }}=1 \Omega$, and the ideal case $Z_{e q}=Z_{v}$.

\section{Controller Design for RL Virtual Impedance}

Instead of the conventional PI controller, the voltage controller is selected as an integrator to avoid the steady-state error together with a pole to increase the gain margin. The controller can be expressed as follows:

$$
C_{v}(s)=\frac{K_{i}}{s \cdot\left(s / \omega_{p}+1\right)}
$$

where $K_{i}$ is the controller gain and $\omega_{p}$ the pole frequency.

For the controller design, the ideal case $Z_{e q}=Z_{v}$ is assumed, that is with $R_{b a t} \rightarrow \infty, \mathrm{H}_{\mathrm{v}}=1, \mathrm{~S}_{\mathrm{v}}=1$ and $\mathrm{G}_{\mathrm{icl}}=1$. Then the controller parameters are obtained for that plant, a cutoff frequency of $0.5 \mathrm{~Hz}$, and a phase margin of $80^{\circ}$.

Once the controller is designed, the compensated open-loop is represented in Fig. 11 using the mentioned RL virtual impedance, and for three different battery resistances $\left(R_{\text {bat } \text { min }}=10 \mathrm{~m} \Omega, R_{\text {bat, } \text { medium }}=100 \mathrm{~m} \Omega, R_{\text {bat, } \max }=1 \Omega\right)$. It can be observed that, for high battery resistances, the voltage response is in line with the specifications, while for very low battery resistances, the control becomes slower. Specifically, the voltage response slows down from $0.49 \mathrm{~Hz}$ for $R_{\text {bat, } \max }=1 \Omega$ up to $0.13 \mathrm{~Hz}$ for $R_{\text {bat, } \min }=10 \mathrm{~m} \Omega$. Comparing these results with the bode plot for the conventional control shown in Fig. 5, it is clear that the plant variability effect has been greatly reduced.

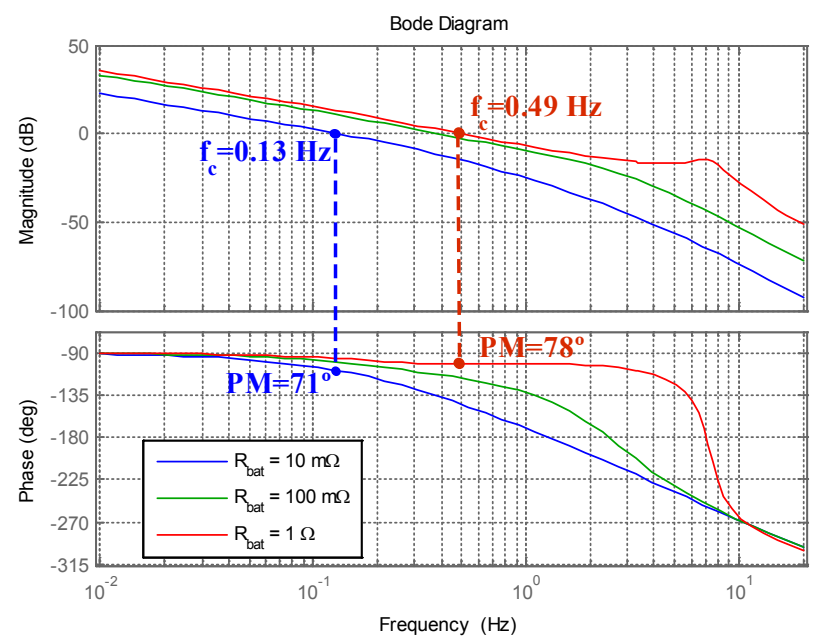

Fig. 11. Bode plot of compensated open loop $\mathrm{C}_{\mathrm{v}} \cdot \mathrm{Z}_{\mathrm{eq}} \cdot \mathrm{H}_{\mathrm{v}}$ for $R_{\text {bat, min }}=10 \mathrm{~m} \Omega$, $R_{\text {bat, } \text { medium }}=100 \mathrm{~m} \Omega, R_{\text {bat, } \max }=1 \Omega$.

\section{Design Procedure and Simulation Results}

The design procedure for the proposed method is summarized in Table II, where the specific values are given for the case presented in the paper. It is worth noting that this is a straightforward design and cannot substitute the whole design presented in this section for a more general approach.

TABLE II

SUMMARIZED DESIGN PROCEDURE

1. Characterize the plant variability. $\quad R_{b a t, \min }=10 \mathrm{~m} \Omega$

$R_{b a t, \max }=1 \Omega$

2. Design the virtual impedance:

i. Assume the use of an RL impedance, $\quad Z_{v}=L \cdot \mathrm{s}+R$ due to its ease of implementation and noise immunity.

ii. As a rule of thumb, assume the resistance equal to the reactance at the voltage cutoff frequency $\omega_{c}$.

$L \cdot \omega_{c}=R$

$Z_{v}=R \cdot\left(\mathrm{s} / \omega_{c}+1\right)$

$\omega_{c}=2 \pi \cdot 0.5 \mathrm{rad} / \mathrm{s}$

iii. From the expressions in Fig. 9, obtain Cond. 1: $R>14.3 \mathrm{~m} \Omega$ the minimum $R$ value which avoids $\quad$ Cond. $2: R>1.05 \mathrm{~m} \Omega$ RHP poles for $R_{b a t}=R_{b a t, \max }$.

iv. Select a low $R$ value but always maintaining a certain Gain Margin $(\mathrm{GM} \geq 6 \mathrm{~dB})$.

$G M=7.8 \mathrm{~dB}$

$R=2.45 \cdot 14.3 \mathrm{~m} \Omega$

$R=35 \mathrm{~m} \Omega$

v. Obtain the $L$ value from the previous

$L=R / \omega_{c}=11.2 \mathrm{mH}$ expression (ii).

3. Design the voltage controller:

i. Assume the use of a controller formed by an integral part to avoid steady-state error plus a pole to increase the gain margin.

ii. Assume that the plant seen by the controller is the virtual impedance (for $R_{\text {bat }} \rightarrow \infty, \mathrm{H}_{\mathrm{v}}=\mathrm{S}_{\mathrm{v}}=\mathrm{G}_{\mathrm{icl}}=1$ ).

iii. Determine $K_{i}$ and $\omega_{p}$ in order to obtain the desired cutoff frequency $\omega_{c}$ and Phase Margin $\left(\mathrm{PM} \geq 60^{\circ}\right)$.

$$
\begin{aligned}
& C_{v}=\frac{K_{i}}{s \cdot\left(s / \omega_{p}+1\right)} \\
& Z_{e q}=Z_{v}=L \cdot s+R \\
& P M=80^{\circ} \\
& K_{i}=110.7 \\
& \omega_{p}=2.20 \mathrm{rad} / \mathrm{s}
\end{aligned}
$$

The proposed control is tested by using PSIM simulation software. The model includes the battery, a boost converter, and a single-phase inverter connected to the grid. The simulation results for different battery resistances are shown in Fig. 12, where the battery voltage and its reference are plotted. 
It can be observed that the voltage response is as designed for $R_{\text {bat,max }}=1 \Omega$ and $R_{\text {bat,medium }}=100 \mathrm{~m} \Omega$, and it becomes slower for $R_{b a t, \text { min }}=10 \mathrm{~m} \Omega$, as predicted by the previous analysis. More precisely, the rise time (from 0 to $100 \%$ for underdamped systems [47]) is $t_{r, 1 \Omega}=860 \mathrm{~ms}, t_{r, 100 \mathrm{~m} \Omega}=940 \mathrm{~ms}$, $t_{r, 10 m \Omega}=3.1 \mathrm{~s}$, greatly improving the results of the conventional control shown in Fig. 6.
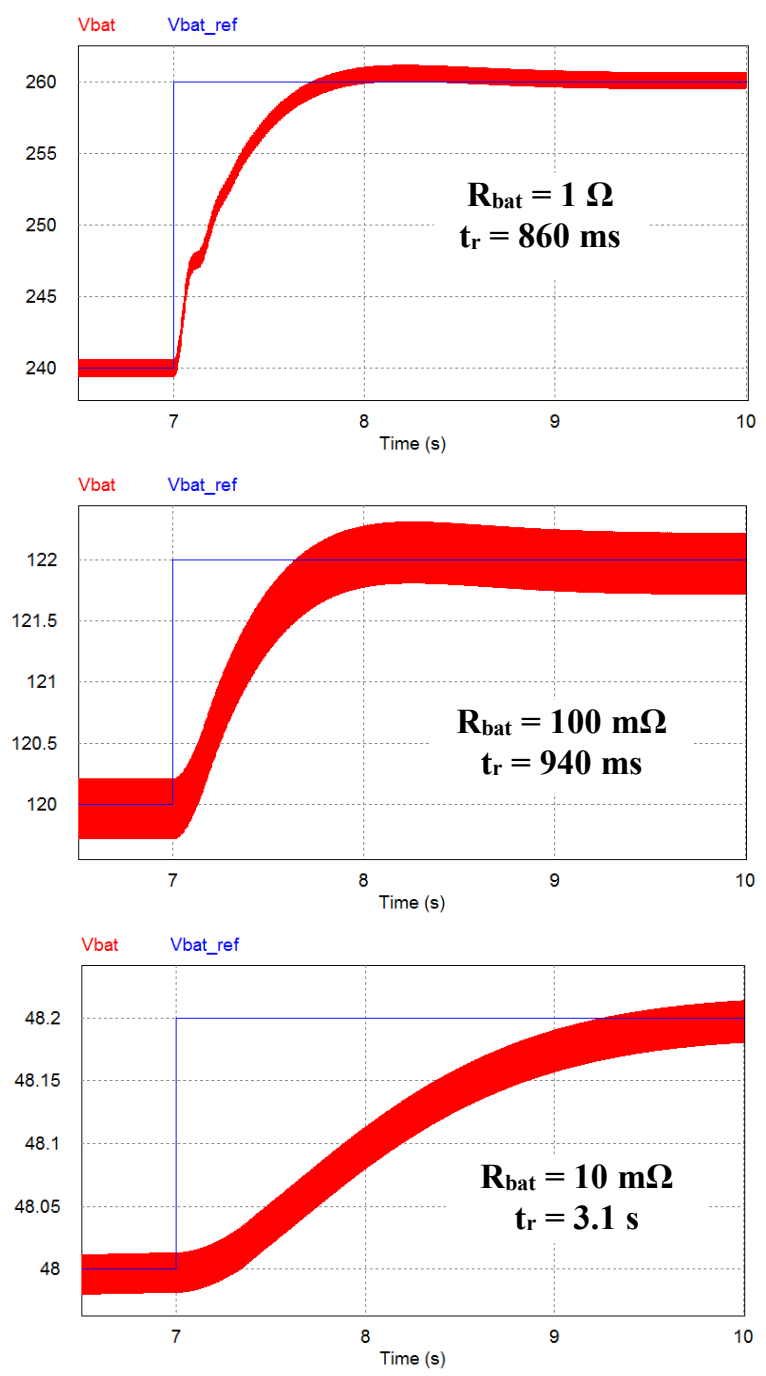

Fig. 12. Simulation results for the proposed battery voltage control with RL virtual impedance, for $R_{\text {bat, } \max }=1 \Omega, R_{\text {bat,medium }}=100 \mathrm{~m} \Omega$ and $R_{\text {bat,min }}=10 \mathrm{~m} \Omega$.

The proposed control is also tested with PSIM for a photovoltaic-based stand-alone system for the same conditions as carried out for the conventional control. The results are plotted in Fig. 13, where the battery voltage evolution after an irradiance rise is shown. As it can be observed, the voltage response is much faster, making it possible to reduce the overvoltage magnitude and duration, when compared to the conventional control results shown in Fig. 7. Specifically, the maximum battery voltage reaches $54.41 \mathrm{~V}$, and the duration of the overvoltage is much shorter (the voltage remains $1.1 \mathrm{~s}$ over 54.1 V), helping to expand the battery lifetime.

In summary, the proposed control is stable and fast enough for every situation, including the scenario with $R_{b a t}=10 \mathrm{~m} \Omega$, where the operating conditions, battery chemistry and technology, and voltage and capacity levels represent the worst case.

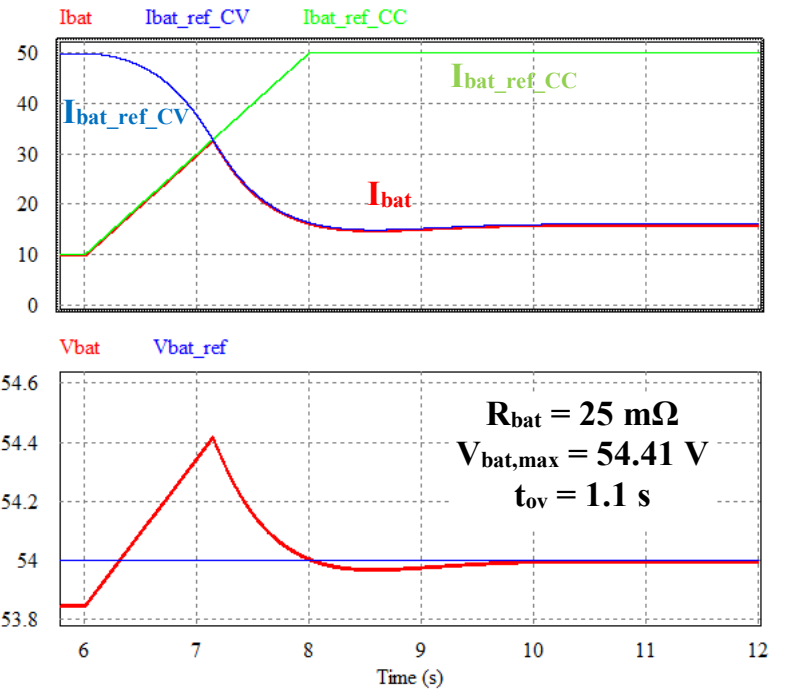

Fig. 13. Simulation results for the proposed battery voltage control with RL virtual impedance after an irradiance rise, for $R_{\text {bat, } \min }=25 \mathrm{~m} \Omega$.

\section{EXPERIMENTAL RESULTS}

In this section, the conventional control and the proposed control for an RL virtual impedance are tested and compared. With this aim, two different batteries are connected through a commercial single-phase inverter to the grid. The first stage of the inverter is a boost converter, whose features are shown in Table I. The specifications of the two batteries are shown in Table III. The photos of the elements used for the experiments are shown in Fig. 14. During the tests, the series resistance was around $R_{\text {bat }}=25 \mathrm{~m} \Omega$ for the lithium-ion battery and around $R_{b a t}=400 \mathrm{~m} \Omega$ for the lead-acid battery.

TABLE III

SPECIFICATIONS OF THE BATTERIES

\begin{tabular}{lll}
\hline Battery & LG Chem RESU 3,3 & Sonnenschein PC 12/180 FT \\
Chemistry & Lithium-ion & Lead-acid \\
State & New & Overused \\
Nominal voltage & $51.8 \mathrm{~V}$ & $120 \mathrm{~V}$ \\
Capacity & $63 \mathrm{Ah}$ & $165 \mathrm{Ah}\left(C_{10}\right)$ \\
Maximum current & $60 \mathrm{~A}$ & $50 \mathrm{~A}$ \\
\hline \hline
\end{tabular}

The conventional voltage control is first validated for the two mentioned batteries. For this purpose, the original inverter control, which consists of an integral controller designed for $R_{\text {bat,medium }}=100 \mathrm{~m} \Omega$ (see Fig. 4 and section II), is not modified. The battery current and voltage are depicted in Fig. 15 for steps in the reference voltage. As can be observed, the control response strongly depends on the battery resistance, becoming too fast and underdamped for the leadacid battery $\left(R_{b a t}=400 \mathrm{~m} \Omega\right)$ and too slow for the lithium-ion battery $\left(R_{b a t}=25 \mathrm{~m} \Omega\right)$. More precisely, the rise time of the voltage response varies from $t_{r}=110 \mathrm{~ms}$ to $t_{r}=3.7 \mathrm{~s}$, and is in both cases very far from the desired performance (using $3 / \omega_{c}$, the rise time should be close to $950 \mathrm{~ms}$ ). 


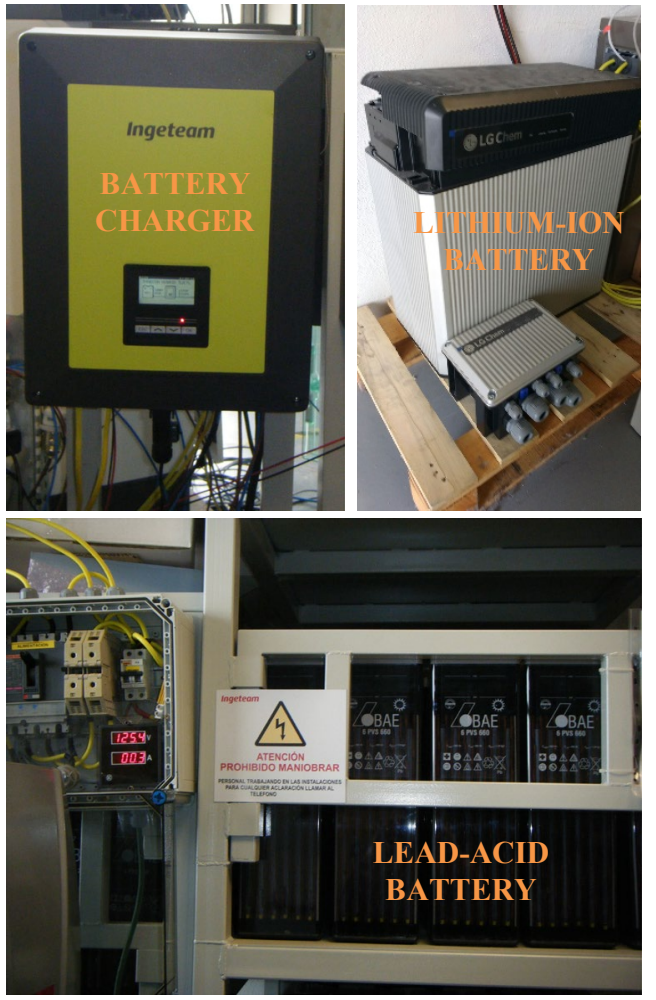

Fig. 14. Battery charger, lithium-ion battery and lead-acid battery used for the experimental setup.

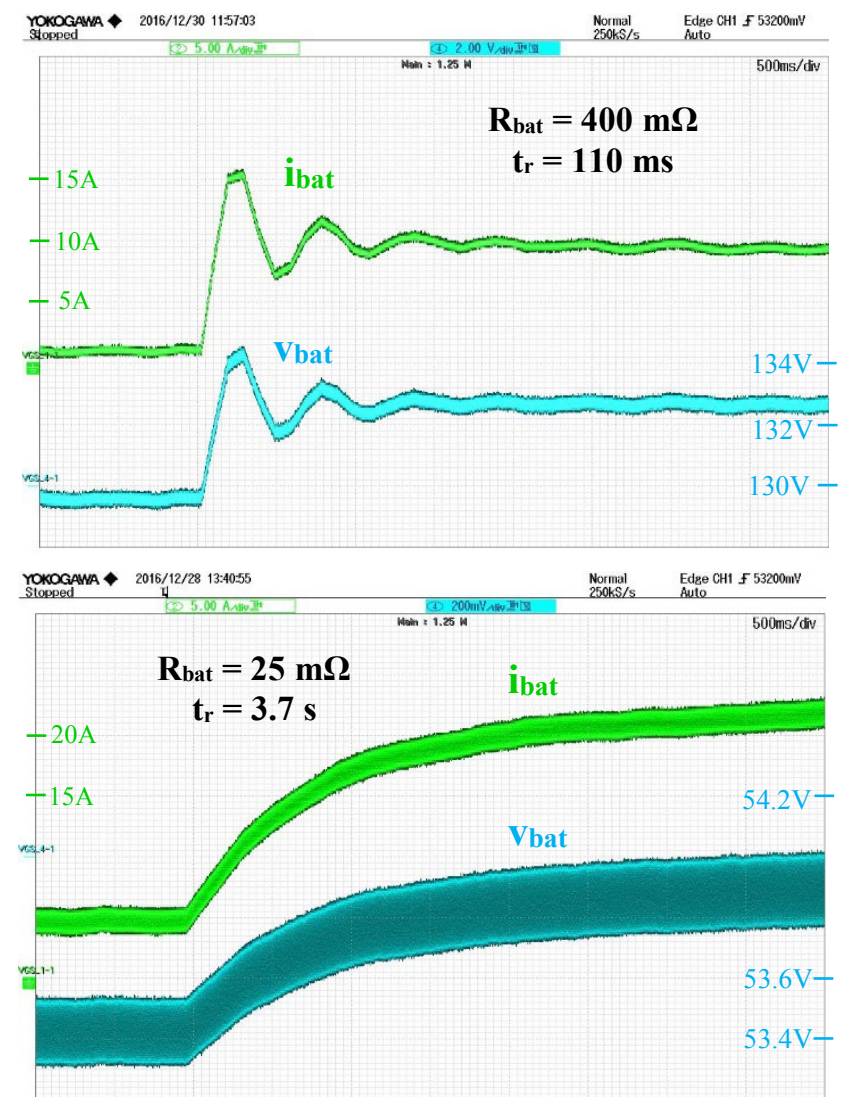

Fig. 15. Experimental results for the conventional battery voltage control, for a lead-acid battery $\left(R_{\text {bat }}=400 \mathrm{~m} \Omega\right)$ and a lithium-ion battery $\left(R_{\text {bat }}=25 \mathrm{~m} \Omega\right)$.
The proposed control is then validated for the case of $\mathrm{RL}$ impedance emulation, with $R=35 \mathrm{~m} \Omega$ and $L=11.2 \mathrm{mH}$. With this aim, the inverter configuration is modified in order to implement the proposed method presented in section III (see Fig. 8(b)). Figure 16 shows the battery current and voltage for steps in the reference voltage. As can be observed, the control response is now less dependent on the battery resistance and close to the design specifications for both the lead-acid and lithium-ion batteries. More precisely, the rise time is $t_{r}=600$ $\mathrm{ms}$ for the lead-acid battery and $\mathrm{t}_{\mathrm{r}}=1.2 \mathrm{~s}$ for the lithium-ion battery, close to the desired performance $\left(t_{r}=950 \mathrm{~ms}\right)$. It is worth noting that, if required, the voltage response variability can be further reduced by decreasing the virtual impedance $(R$ and $L$ values), at the cost of deteriorating the noise immunity.

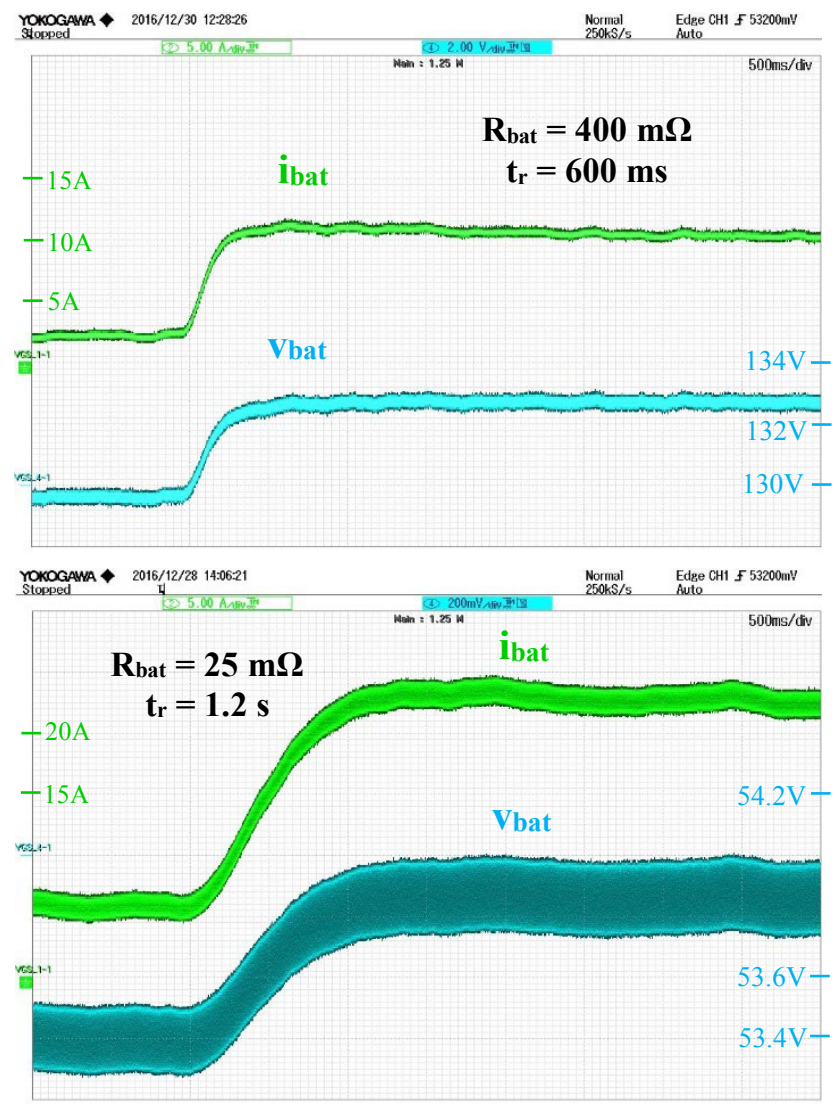

Fig. 16. Experimental results for the proposed battery voltage control with RL virtual impedance, for a lead-acid battery $\left(R_{b a t}=400 \mathrm{~m} \Omega\right)$ and a lithium-ion battery $\left(R_{\text {bat }}=25 \mathrm{~m} \Omega\right)$.

\section{CONCLUSION}

Effective battery voltage regulation is a fundamental requirement in order to extend the battery lifetime. However, it is difficult to obtain a parameter-independent voltage control since the battery impedance can vary drastically depending on battery technology, operating point, aging, and series-parallel cell connection.

As proposed in this paper, emulating a small virtual impedance in parallel with the battery makes it possible to greatly reduce the plant variability seen by the controller. Hence, a simple linear controller achieves the same voltage response for completely different battery systems and 
conditions, as shown in the experimental results for a $25 \mathrm{~m} \Omega$ impedance lithium-ion battery and a $400 \mathrm{~m} \Omega$-impedance leadacid battery.

Among the virtual impedances which have been considered, the RL one is best suited for practical applications thanks to its noise immunity and simple implementation. When dealing with applications in which the battery impedance can reach even lower values, then a virtual impedance in series with the battery impedance could also be emulated to further reduce plant variability.

This method can be applied to other current-mode controlled systems with highly variable impedance such as photovoltaic systems, small wind turbines or fuel cells.

\section{ACKNOWLEDGMENT}

The authors gratefully acknowledge the financial and ongoing support of INGETEAM POWER TECHNOLOGY.

\section{REFERENCES}

[1] S. Jeong, Y. J. Jang and D. Kum "Economic analysis of the dynamic charging electric vehicle," IEEE Transactions on Power Electronics, vol. 30 , no. 11 , pp. 6368-6377, Nov. 2015

[2] I.-O. Lee, "Hybrid PWM-resonant converter for electric vehicle onboard battery chargers," IEEE Transactions on Power Electronics, vol. 31, no. 5, pp. 3639-3649, May 2016.

[3] I. de la Parra, J. Marcos, M. García and L. Marroyo, "Control strategies to use the minimum storage requirement for $\mathrm{PV}$ power ramp-rate control," Solar Energy, vol. 111, pp. 332-343, Jan. 2015.

[4] C. Mateo, J. Reneses, A. Rodriguez-Calvo, P. Frías and A. Sánchez, "Cost-benefit analysis of battery storage in medium-voltage distribution networks," IET Generation, Transmission \& Distribution, vol. 10, no. 3, pp. 815-821, Feb. 2016.

[5] C.-L. Nguyen, H.-H. Lee and T.-W. Chun, "Cost-optimized battery capacity and short-term power dispatch control for wind farm," IEEE Transactions on Industry Applications, vol. 51, no. 1, pp. 595-606, Jan. 2015.

[6] A. Urtasun, P. Sanchis and L. Marroyo, "State-of-charge-based droop control for stand-alone systems with distributed energy storage," Energy Conversion and Management, vol. 106, pp. 709-720, Dec. 2015.

[7] A. Urtasun, P. Sanchis, and L. Marroyo, "Frequency-based energymanagement strategy for stand-alone systems with distributed battery storage," IEEE Transactions on Power Electronics, vol. 30, no. 9, pp. 4794-4808, Sept. 2015.

[8] M. Pereira, D. Limon, D. M. de la Peña, L. Valverde and T. Alamo, "Periodic economic control of a nonisolated microgrid," IEEE Transactions on Industrial Electronics, vol. 62, no. 8, pp. 5247-5255, Aug. 2015.

[9] Y. Han, H. Li, P. Shen, E. A. A. Coelho and J. M. Guerrero, "Review of active and reactive power sharing strategies in hierarchical controlled microgrids," IEEE Transactions on Power Electronics, vol. 32, no. 3, pp. 2427-2451, Mar. 2017.

[10] H. Farzin, M. Fotuhi-Firuzabad and M. Moeini-Aghtaie, "A practical scheme to involve degradation cost of lithium-ion batteries in vehicle-togrid applications," IEEE Transactions on Sustainable Energy, vol. 7, no. 4, pp. 1730-1738, Oct. 2016.

[11] B. Zhou, X. Liu, Y. Cao, C. Li, C. Y. Chung and K. W. Chan, "Optimal scheduling of virtual power plant with battery degradation cost," IET Generation, Transmission \& Distribution, vol. 10, no. 3, pp. 712-725, Feb. 2016.

[12] B. Xu, A. Oudalov, A. Ulbig, G. Andersson and D. S. Kirschen, "Modeling of lithium-ion battery degradation for cell life assessment," IEEE Transactions on Smart Grid, early access, DOI 10.1109/TSG.2016.2578950

[13] F. Teseco, L. Mariam, M. Basu, A. Casavola and M. F. Conlon, "Economic model predictive control-based strategies for cost-effective supervisión of community microgrids considering battery lifetime," IEEE Journal of Emerging and Selected Topics in Power Electronics, vol. 3, no. 4, pp. 1067-1077, Dec. 2015.
[14] I. Duggal and B. Venkatesh, "Short-term scheduling of thermal generators and battery storage with depth of discharge-based cost model," IEEE Transactions on Power Systems, vol. 30, no. 4, pp. 21102118, July 2015.

[15] H. Fang, Y. Wang and J. Chen, "Health-aware and user-involved battery charging management for electric vehicles: linear quadratic strategies," IEEE Transactions on Control Systems Technology, vol. 25, no. 3, pp. 911-923, May 2017.

[16] B. Suthar, V. Ramadesigan, S. De, R. D. Braatz and V. R. Subramanian, "Optimal charging profiles for mechanically constrained lithium-ion batteries," Physical Chemistry Chemical Physics, vol. 16, no. 1, pp. 277-287, Jan. 2013.

[17] H. A. Catherino, F. F. Feres and F. Trinidad, "Sulfation in lead-acid batteries," Journal of Power Sources, vol. 129, no. 1, pp. 113-120, Apr. 2004.

[18] X. Qu, H. Han, S.-C. Wong, C. K. Tse and W. Chen, "Hybrid IPT topologies with constant current or constant voltage output for battery charging applications," IEEE Transactions on Power Electronics, vol. 30, no. 11, pp. 6329-6337, Nov. 2015.

[19] S. Amstrong, M. E. Glavin and W. G. Hurley, "Comparison of battery charging algorithms for stand alone photovoltaic systems," in 2008 Power Electronics Specialists Conference, pp. 1469-1475, July 2008.

[20] B. J. Huang, P. C. Hsu, M. S. Wu and P. Y. Ho, "System dynamic model and charging control of lead-acid battery for stand-alone solar PV systems," Solar Energy, vol. 84, no. 5, pp. 822-830, May 2010.

[21] T. A. Nguyen, X. Qiu, J. D. Guggenberger II, M. L. Crow and A. C. Elmore, "Performance characterization for photovoltaic-vanadium redox battery microgrid systems," IEEE Transactions on Sustainable Energy, vol. 5, no. 4, pp. 1379-1388, Oct. 2014.

[22] X. Qiu, T. A. Nguyen, J. D. Guggenberger, M. L. Crow and A. C. Elmore, "A field validated model of a vanadium redox flow battery for microgrids," IEEE Transactions on Smart Grids, vol. 5, no. 4, pp. 1592 1601, July 2014.

[23] N. Tashakor, E. Farjah and T. Ghanbari, "A bi-directional battery charger with modular integrated charge equalization circuit," IEEE Transactions on Power Electronics, vol. 32, no. 3, pp. 2133-2145, Mar. 2017.

[24] P.-J. Liu and C.-H. Yen, "A fast charging switching-based charger with adaptive hybrid duty cycle control for multiple batteries," IEEE Transactions on Power Electronics, vol. 32, no. 3, pp. 1975-1983, Mar. 2017.

[25] R. J. Wai and S. J. Jhung, "Design of energy-saving adaptive fastcharging control strategy for $\mathrm{Li}^{-\mathrm{FePO}_{4}}$ battery module," IET Power Electronics, vol. 5, no. 9, pp. 1684-1693, Nov. 2012.

[26] A. M. A. Haidar and K. M. Muttaqi, "Behavioral characterization of electric vehicle charging loads in a distribution power grid through modeling of battery chargers," IET Transactions on Industry Applications, vol. 52, no. 1, pp. 483-492, Jan. 2016.

[27] P. H: V. Quang, T. T. Ha and J.-W. Lee, "A fully integrated multimode wireless power charger IC with adaptive supply control and built-in resistance compensation," IET Transactions on Industrial Electronics, vol. 62 , no. 2 , pp. 1251-1261, Feb. 2015.

[28] S. G. Tesfahunegn, O. Ulleberg, T. M. Undeland and P. J. S. Vie, “A simplified battery charge controller for safety and increased utilization in standalone PV applications," in $37^{\text {th }}$ IEEE Photovoltaic Specialists Conference, pp. 2441-2447, June 2011.

[29] D. Pavkovic, M. Lobrovic, M. Hrgetic, A. Komljenovic and V. Smetko, "Battery current and voltage control system design with charging application," in 2014 IEEE Conference on Control Applications, pp. 1133-1138, Oct. 2014.

[30] S. Biswas, L. Huang, V. Vaidya, K. Ravichandran, N. Mohan and S. V. Dhople, "Universal current-mode control schemes to charge Li-ion batteries under DC/PV source," IEEE Transaction on Circuits and Systems-I: Regular Papers, vol. 63, no. 9, pp. 1531-1542, Sep. 2016.

[31] A. A.-H. Hussein and I. Batarseh, "A review of charging algorithms for nickel and lithium battery chargers," IEEE Transactions on Vehicular Technology, vol. 60, no. 3, pp. 830-838, Mar. 2011.

[32] H. Rahimi-Eichi and M.-Y. Chow, "Adaptive parameter identification and state-of-charge estimation of lithium-ion batteries," in $38^{\text {th }}$ IEEE Industrial Electronics Society Conference, pp. 4012-4017, Oct. 2012.

[33] H. M. O. Filho, D. S. Oliveira and C. E. Alencar e Silva, "Three-stage static power converter for battery charging feasible for small wind energy conversion systems," IEEE Transactions on Industry Applications, vol. 50, no. 5, pp. 3602-3610, Sep. 2014. 
[34] Y.-D. Lee and S.-Y. Park, "Rapid charging strategy in the constant voltage mode for a high power Li-ion battery," in 2013 IEEE Energy Conversion Congress and Exposition, pp. 4725-4731, Sep. 2013.

[35] A. Urtasun, P. Sanchis, D. Barricarte and L. Marroyo, "Energy management strategy for a battery-diesel stand-alone system with distributed PV generation based on grid frequency modulation," Renewable Energy, vol. 66, pp. 325-336, June 2014.

[36] J. Jiang, C. Zhang, J. Wen, W. Zhang and S. M. Sharkh, "An optimal charging method for Li-ion batteries using a fuzzy-control approach based on polarization properties," IEEE Transactions on Vehicular Technology, vol. 62, no. 7, pp. 3000-3009, Sep. 2013.

[37] P. Albertos, A. Sala and M. Olivares, "Fuzzy logic controllers. Methodology, advantages and drawbacks," in Congreso Español sobre Tecnologías y Lógica Fuzzy, Dec. 2000.

[38] K. De Gussemé, D. M. Van de Sype, A. P. M. Van den Bossche and J. A. Melkebeek, "Digitally controlled boost power-factor-correction converters operating in both continuos and discontinuos conduction mode," IEEE Transactions on Industrial Electronics, vol. 52, no. 1, pp. 88-97, Feb. 2005.

[39] A. Urtasun, P. Sanchis and L. Marroyo, "Adaptive voltage control of the DC/DC boost stage in PV converters with small input capactor," IEEE Transactions on Power Electronics, vol. 28, no. 11, pp. 5038-5048, Nov. 2013.

[40] S.-Y. Cho, I.-O. Lee, J.-I. Baek and G.-W. Moon, "Battery impedance analysis considering DC component in sinusoidal ripple-current charging," IEEE Transactions on Industrial Electronics, vol. 63, no. 3, pp. 1561-1573, Mar. 2016.

[41] M. Einhorn, F. V. Conte, C. Kral and J. Fleig, "Comparison, selection and parametrization of electrical battery models for automotive applications," IEEE Transactions on Power Electronics, vol. 28, no. 3, pp. 1429-1437, Mar. 2013.

[42] N. Somakettarin and T. Funaki, "Parameter extraction and characteristics study for manganese-type lithium-ion battery," International Journal of Renewable Energy Research, vol. 5, no. 2, pp. 464-475, June 2015.

[43] Y. Jing, W. Xuezhe, D. Haifeng, Z. Jiangong and X. Xudong, "Lithiumion battery internal resistance model based on the porous electrode theory," in 2014 IEEE Vehicle Power and Propulsion Conference, pp. 1-6, Oct. 2014.

[44] J. D. Dogger, B. Roossien and F. D. J. Nieuwenhout, "Characterization of Li-ion batteries for intelligent management of distributed gridconnected storage," IEEE Transactions on Energy Conversion, vol. 26, no. 1, pp. 256-263, Mar. 2011.

[45] S. Schaeck, A. O. Stoermer, F. Kaiser, L. Koehler, J. Albers and H. Kabza, "Lead-acid batteries in micro-hybrid applications. Part I. Selected key parameters," Journal of Power Sources, vol. 196, no. 3, pp. 1541-1554, Feb. 2011.

[46] T. Dragicevic, J. M. Guerrero, J. C. Vasquez, and D. Skrlec, "Supervisory control of an adaptive-droop regulated DC microgrid with battery management capability," IEEE Transactions on Power Electronics, vol. 29, no. 2, pp. 695-706, Feb. 2014.

[47] W. S. Levine, The Control Handbook, CRC Press, ISBN 0-8493-8570-9, 1996.

\section{BIOGRAPHIES}

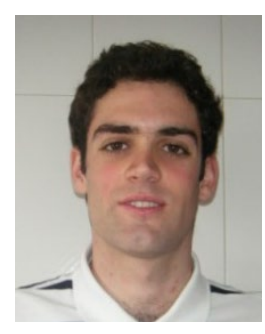

Andoni Urtasun (S'11-M'16) was born in Pamplona, Spain, in 1987. He received the M.Sc. degree in electrical engineering from the Public University of Navarre (UPNA), Pamplona, Spain, and from the Institut National Polytechnique de Toulouse, Toulouse, France, both in 2010, and the $\mathrm{Ph} . \mathrm{D}$. degree in electrical engineering from the UPNA in 2015.

In 2010, he joined the Electrical Engineering, Power Electronics and Renewable Energy research group, UPNA, where he is currently Assistant Professor. During 2014, he was visiting scholar in the University of Sydney, Australia. His research interests include power electronics and renewable energies.

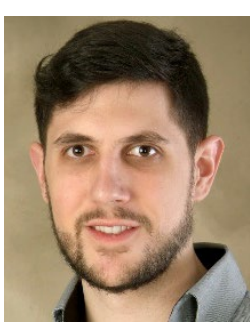

Alberto Berrueta (S'15) was born in Pamplona, Spain, in 1989. He received the M.Sc. degree in electrical engineering from the Public University of Navarra, Spain, in 2013. He is currently working toward the Ph.D. degree at the Public University of Navarra.

In 2013, he joined the Electrical Engineering, Power Electronics and Renewable Energy Research Group, Public University of Navarra. His research interests include electrochemical modelling, thermal performance and aging of lithium-ion

batteries and supercapacitors

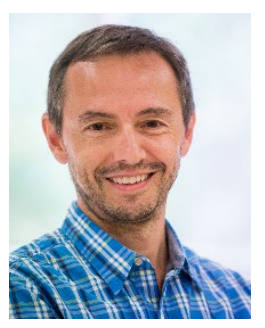

Pablo Sanchis (M'03-SM'12) received the M.Sc. and $\mathrm{Ph} . \mathrm{D}$. degrees in electrical engineering in 1995 and 2002, respectively, and the M.Sc. degree in management and business administration in 1994, all from the Public University of Navarra, Pamplona, Spain.

From 1996 to 1998, he worked as a Guest Researcher at Delft University of Technology, The Netherlands, on the field of control of electric machines. In 1998, he joined the Department of Electrical and Electronic Engineering at the Public University of Navarra, Spain, where he is currently Associate Professor. He is also Director of the UPNA Chair for Renewable Energies and Director of the Research Resources and Structures Unit of the university. Previously, he was Vice Dean of the School of Industrial and Telecommunications Engineering.

He has been involved in more than 70 research projects both with public funding and in co-operation with industry and is the co-inventor of 8 patents. $\mathrm{He}$ has also co-authored more than 120 papers and contributions in international journals and conferences, and supervised $9 \mathrm{PhD}$ thesis. His research interests include renewable energies, power electronics, electric energy storage technologies, grid integration of renewable energies and electric microgrids.

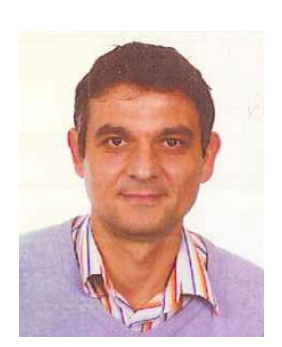

Luis Marroyo (M'04) received the M.Sc. degree in electrical engineering in 1993 from the University of Tolouse, France, and the Ph.D. degree in electrical engineering in 1997 from the UPNA, Spain, and in 1999 from the LEEI-ENSEEIHT INP Toulouse, France.

From 1993 to 1998, he was Assistant Professor at the Department of Electrical and Electronic Engineering of the UPNA, where he currently works as Associate Professor, since 1998. He is the head of the INGEPER research group. He has been involved in more than 60 research projects mainly, in co-operation with industry, he is the co-inventor of 15 international patents and co-authored of more than 100 papers in international journals and conferences. His research interests include power electronics, grid quality and renewable energy. 
IEEE TRANSACTIONS ON POWER ELECTRONICS 